\title{
Maithili English: Some Characteristic Features
}

\section{Dr. Pooja Roy}

T. M. Bhagalpur University, Bhagalpur, Bihar, India

\begin{abstract}
The present paper aims to discuss the vowels, consonants and diphthongs of Maithili English. It also explains some supra segmental features of English which causes problem for Maithili speakers of English and makes their speech unintelligible. Besides this it also tries to explain the interference of Maithili in the speech of Maithili speakers of English in Bihar and find out the growing trend of Maithili English even in work place because of Maithili speakers loyalty to their language.
\end{abstract}

Keywords - Phonology, Maithili speakers, interference, consonants, vowels, pronunciation, unintelligible.

\section{INTRODUCTION}

\section{Maithili English}

Maithili English is a term restricted to that variety of Indian English or to be more precise Bihari English which is spoken by people whose mother tongue (L1) is Maithili. Maithili is the richest of all the dialects in Bihar and has the tone and temper of its own. In tone, temper and script, it is very near to Bengali and the heavy interference of Maithili is also observed in their speech. Naturally it is desirable to study the sound system and the phonology of Maithili both in the historical as well as the phonological context.

\subsection{Maithili Language}

Maithili is a language derived from the word 'Mithila', an ancient kingdom governed by King Janak. It is spoken in the eastern part of India, mainly in the Indian state of Bihar and the eastern Terai region of Nepal. It is an offshoot of the Indo-Iranian, a branch of the Indo European languages. Linguists consider Maithili to be an Eastern Indic language and thus a different language from Hindi which is central Indic in origin. According to the 2001 census in India $^{1}, 12,179,122$ people speak the Maithili language, but various organizations have strongly argued that the actual number of Maithili speakers is much more than the official data suggests. Earlier Maithili was considered a "dialect" of both Hindi and Bengali but thanks to an active movement calling for official status for language, it is now included in $8^{\text {th }}$ schedule of the Indian constitution, which now allows the language to be used in education, government and the other official contexts. Maithili has a very rich literary and cultural heritage and was recognized by the Sahitya Academy much earlier. After its inclusion in the $8^{\text {th }}$ schedule of the Indian constitution, now it is one of the 22 National languages of India.

Maithili is now a language, having a large Maithilispeaking community with a rich literature. Poet Vidyapati is the most famous literary figure in Maithili. He is credited for raising the importance of 'peoples language', i.e. Maithili in the official work of the state by influencing the Maharaja of Darbhanga with the quality of his poetry.

\subsection{History of Maithili language}

As mentioned earlier the name Maithili is derived from the word Mithila, an ancient kingdom of which King Janaka was the ruler. Maithili is also one of the names of Sita, the wife of king Rama and daughter of king Janaka.

History has it those scholars in Mithila used Sanskrit for their literary work and Mathili was the language of the common folk (Abahatta). The earliest work in Maithili appears to be 'Varn Ratnakar' by Jyotirishwar Thakur dated about $1224 \mathrm{AD}$.

The Medieval age of Maithili has some of the prominent writers like- Ganesh, Padmanabh, Chandeshwar, Vireshwar, Vidyapati, Vachaspati, Pakshadhar, Ayachi, Udayan etc.

Modern Maithili Literature is also very rich in all the genres-fiction, poetry, drama, and criticism. Modern Maithili Theatre, "Aripam" was started by shri Kaushal Kumar Das. Modern Maithili came into its own after Sir George Abraham Grierson, Irish linguist and civil servant, tirelessly researched Maithili folklore and wrote its grammar. 


\subsection{Maithili Speech Area}

Maithili speech area comprises of almost all the districts of north Bihar except Bettiah and Motihari, namely Katihar, Purnea, Madhepura, Saharsa, Supaul, Khagaria, Begusarai, Darbhanga, Samastipur, Sitamarhi, Jainagar, Madhubani etc. It is also widely used in the valley areas of Nepal, particularly bordering India.

\subsection{Scripts}

According to Wikipedia, the free encyclopedia ${ }^{2}$, "Maithili was traditionally written in the Maithili script (also known by the names Tirhuta and Mithilakshar) and Kaithi script". However, in the modern times Devnagari script is most commonly used. Efforts are also being made to preserve the Maithili script and to develop it for use in digital media by encoding the script in the Unicode standard, for which a proposal has recently been submitted.

\subsection{Grammar, Morphology and Phonology}

Lots of studies have also been conducted in the areas of Maithili language, grammar, morphology, syntax and phonology. Maithili is also widely available on internet, but not precisely in the area of phonology.

\section{THE PHONOLOGY OF MAITHILI}

Maithili phonology is not much different from the phonologies of Hindi, Magahi, Bhojpuri and Angika with a remarkable thing that it is more akin to Sanskrit. It has $9+4=13$, vowel sounds and 33 consonant sound. Like Magahi, Maithili too does not have diphthongs.

\subsection{Vowels}

The primary 9 vowel sounds in Maithili are:

$$
\text { /ə, I, v, ri:, Iri:, e, æ, o, o:/ }
$$

One special feature to note here is that four vowels namely /a:, u:, i:, $\tilde{a} /$ are described as additional vowel sounds in Maithili.

\subsection{Consonants}

There are 33 consonants in Maithili which are given in a chart below:

\begin{tabular}{|l|l|l|l|l|l|}
\hline Kabarg & K & Kh & g & gh & y \\
\hline Chabarg & C & Ch & j & Jh & y \\
\hline Tabarg & T & Th & D & Dh & N \\
\hline tabarg & t & th & D & dh & n \\
\hline Pabarg & p & ph & B & bh & m \\
\hline Antasth & y & r & I & W & \\
\hline Ushm & s & x & S & h & \\
\hline
\end{tabular}

Maithili Consonant Chart

\section{THE INTERFERENCE OF MAITHILI IN THE SPEECH OF MAITHILI SPEAKERS OF ENGLISH IN BIHAR}

To find out the interference of Maithili in the speech of Maithili speakers of English, I have made a parameter taking into consideration the pronunciation at the following levels:

\subsection{Sounds}

(a) vowels, (b) diphthongs, (c) consonants, (d) conjuncts, (e) length of vowels sounds, (f) aspiration, (g) silencing of consonants.

\subsection{Stress}

(a) word stress, (b) sentence stress, (c) stress in connected speech 


\subsection{Tone and Intonation}

\subsection{Weak Forms}

\subsection{Use of Suffixes}

\subsection{Sounds}

\section{(a) Vowels}

It is observed that Maithili speakers have problem in the pronunciation of four vowel sounds $/ 3: /, / \mathrm{p} /, / \mathrm{J}: /$ and $/ \partial /$. The frequent tendency of Maithili speakers is to replace /3:/ with / $/ 2+\mathrm{r} / \mathrm{g} / \mathrm{p}$ /and / $/$ :/ with /o/ and /o:/ and / / / with $/ \Lambda /$. The use of $/ \partial /$ is hardly observed in the speech of Maithili speakers even in common words like ago and river. Other distinct feature is the use of additional vowel sounds / $/$ / and /e/ in words like station, school, sky etc. One more very distinct feature of the speakers of Maithili English observed is the more rounding of lips, more frequency of rounding and rounding of lips even in the pronunciation of vowel sound like /3:/ and / $/$. Maithili is very akin to Bengali and Bengalies frequently use rounded vowels simply because /a/ is not that widely used in Bengali.

\section{(b) Diphthongs}

This is the area where the majority of Bihari speakers have problem simply because Hindi does not have all the RP diphthongs and also because the speakers are not conscious enough to use diphthongs in their speech. Bihari in general tend to use pure vowels only except for /a I/ and /av/.

\section{(c) Consonants}

Eight RP consonants sounds /f, $, 0, \partial, \mathrm{z}, \int, 3$ and w/ are common problems with Bihari speakers. This is because of the heavy interference of the mother tongue (L1) in their speech. Naturally there is a tendency to pronounce these consonants the way they pronounce these in their mother tongue replacing /f, v/ with Hindi /Ph, bh/, / $\theta$, / / with /th, d/, /z/ with /dz/, /J/ with /s/, /3/ with /dz/ and /w/ with /v/ or even /b/.

\section{(d) Conjuncts}

Conjuncts are also known as consonant clusters cause problem for Maithili speaker of English. They face problem in the pronunciation of simple words having a cluster of any two consonants like "concentrated" which has a /t/, /r/ cluster. Instead of pronouncing "concentrated", most speakers pronounce "concentred" and "concentrated" etc.

\section{(e) Length of the Vowel sounds}

It is observed that Maithili speakers of English generally fail to make clear distinction between short and long vowels and make a fool of themselves in the pronunciation of words like, full and fool, lip and leap, hip and heap etc. The use of one for the other affects intelligibility as well. Very common examples being:

/ri:vər/ for /rivə/, /Iskul/ for/sku:1/, /si:ti:/ for /sitı/ etc.

One more remarkable feature of Maithili speakers is the preference for short vowels even at places where the use of the short vowel makes their speech funny.

\section{(f) Aspiration}

In English the bilabial plosives /p, t, k/ are aspirated in the word initial and stressed position but Maithili speakers of English hardly use aspiration in their speech.

\section{(g) Silent Consonants}

Silencing of consonants in RP is a very common and natural phenomenon. There are also certain fixed rules for the silencing of consonants. Some glaring examples are bomb, tomb, foreign etc. but unfortunately very few Maithili speakers of English are aware of silent consonants. Unawareness of this feature naturally makes their speech highly unintelligible.

\subsection{Stress}

Maithili speakers of English hardly found to be conscious about giving proper stress in their connected speech. If they will take full care of proper stress, $50 \%$ of their errors of spoken English can be rectified because wrong stress causes semantic problems and affect intelligibility.

\subsection{Tone and Intonation}

Tone and Intonation is and important feature of Standard English which affects intelligibility and acceptability of spoken English and causes great semantic problem because English is a stress-timed language and rhythm plays an important role in in.

But unfortunately Maithili speakers of English do not maintain the tone and intonation of SIE in their speech.

\subsection{Weak Forms}

Use of weak forms makes the speech intelligible and impressive particularly in connected/rapid speech. The unawareness of this feature naturally makes someone's speech bookish and mechanical. But since people in Bihar hardly get a chance to interact with the native speakers of 
English, so they fail to cultivate this feature of English in their speech.

Very few Maithili speakers of English are aware of weak forms and pronounce it in their normal speech with ease, confidence and comfort.

\subsection{Use of suffixes}

Certain suffixes in English are pronounced in three different ways in three different environments. The past tense suffix '-d' or '-ed' can be pronounced as $/ \mathrm{t} / \mathrm{h} / \mathrm{d} /, / \mathrm{Id} /$. Similarly the suffix '-s' or '-es' can be pronounced as $/ \mathrm{s} /, / \mathrm{z} /$ and /ız/. For example /tpkt/, /pleId/, /wantıd/, /boks/, /pleız/, /rəoziz/ etc.

But I have observed that Maithili speakers of English care a little about such features of English speech. Only few speakers have some awareness of this feature.

\section{CONCLUSION}

To conclude it can be say that the Maithili speakers of English have problem in pronunciation of vowel sounds like /3:/, / $\mathrm{p} /, / \mathrm{J}: /$ and /ə/ and consonant sounds like: /f, v, $\theta$, , $\mathrm{z}, \int, 3$ and $\mathrm{w} /$. They also have problem in proper use of some Supra Segmental Features like: Stress, Tone, and Intonation, Conjuncts, Length of Vowel Sound, Weak Forms, Silent Consonants, Aspiration and Suffixes etc. But in spite of all the problems if they are aware of the unconscious errors they make in the pronunciation of English sounds, the process of unlearning will automatically start and they would definitely be able to pronounce the vowels, consonants and diphthongs and other important feature of English with care and comfort and their language will become intelligence and acceptable. To make their speech intelligible, impressive and acceptable they should try to be more conscious about their errors and do continuous practice to improve their spoken English.

\section{REFERENCES}

[1] Census of India $<$ http://www.censusindia.gov.in/census_Data_2001.

[2] Maithili Language <Wikipedia,the free Encyclopedia

[3] Census of India .opp.cited.

[4] Shiromani, R.k (1987) The Teaching of English as a Second Language/Foreign Language. Ambition, Journal of IFL, Taiz Yamen.

[5] Balasubramaniam T. (1981) A Textbook of English Phonetics for Indian Students, Hyderabad: Macmillan.
[6] Bansal, R.K. (1972) Spoken English for India. Hyderabad: Orient Longman.

[7] Bolinger, D.L. (1972) Intonation, Harmondsworth: Penguin.

[8] Chomsky, Nand M. Halle (1968) The Sound Pattern of English. New York: Harper and Row. 